\title{
Clinical features and outcome of Covid-19 in individuals without Comorbidities. Do children have the advantage?
}

\author{
Kumar A. ${ }^{1 *}$, Kumari N. ${ }^{2}$, Kumar Singh R. ${ }^{3}$, Kumar A. ${ }^{4}$, Singh V. ${ }^{5}$ \\ DOI: https://doi.org/10.17511/ijpr.2021.i02.04 \\ 1* Abhishek Kumar, Senior specialist, Department of Pediatrics, Central Hospital, Ramgarh, Jharkhand, India. \\ 2 Nilu Kumari, Specialist, Department of Pediatrics, Central Hospital, Ramgarh, Jharkhand, India. \\ 3 Ranjeet Kumar Singh, Senior specialist and Head, Department of Medicine, Central Hospital, Ramgarh, Jharkhand, India. \\ ${ }^{4}$ Alok Kumar, Senior specialist, Department of Pathology, Central Hospital, Ramgarh, Jharkhand, India. \\ 5 V K Singh, CMO Incharge, , Central Hospital, Ramgarh, Jharkhand, India.
}

Objective: Information regarding clinical characteristics and the natural course of COVID-19 amongst individuals without comorbidities is scarce. We therefore conducted a retrospective observational study to decipher the disease profile in two different age groups, middle-aged (40-59 years) and children (up to 12 years). Method: Study was conducted by reviewing the medical records of all patients in the desired age groups and excluding all those with preexisting illness (called comorbidities). Result: A total of 154 and 27 patients were enrolled and studied in the middle-aged adults and children group respectively. Males dominated in both groups with a sex ratio of 2.9 in adults and 1.7 in children. Most of the children (92.5\%) had a history of exposure from an infected family member, while in the adult group history of contact was present in $71.4 \%$ of patients. $62.9 \%$ of children had an asymptomatic infection which was significantly higher than $22.8 \%$ in adults. Cough and fever were the most common symptoms in both age groups, but adults were more likely to have respiratory complaints when compared with children.11 $(7.1 \%)$ patients in the adult group had severe disease while in the children group none had severe disease. Similarly in the adult group 11 patients required ICU admission, but none in the children group. The mean duration of RTPCR positivity was similar in both groups. There was $1(0.6 \%)$ expiry in the adult group whereas none in children. Conclusion: Healthy individuals in both middle-aged and children group tend to have milder disease and both harbour the virus for the almost same duration but adults are more symptomatic in comparison to children and hence children are more likely to be potential asymptomatic carrier and transmitter of infection.

Keywords: COVID-19, Comorbidities, RTPCR, Middle aged, Children

\section{Corresponding Author}

Abhishek Kumar, Senior specialist, Department of Pediatrics, Central Hospital, Ramgarh, Jharkhand, India.

Email: drabhicare@gmail.com

\section{How to Cite this Article}

Kumar A, Kumari N, Singh RK, Kumar A, Singh VK. Clinical features and outcome of Covid-19 in individuals without Comorbidities. Do children have the advantage?. Int J Med Res Rev. 2021;8(2):8893.

\section{Available From}

https://pediatrics.medresearch.in/index.php/ijpr/arti cle/view/667
To Browse

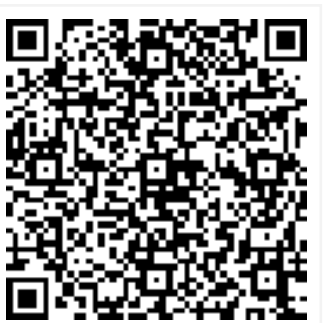

Manuscript Received 2021-03-21

Conflict of Interest No
Review Round 1 2021-03-29

Funding

\section{Review Round 2 2021-04-09 \\ Ethical Approval Yes}

Review Round 3

Plagiarism X-checker $6 \%$
Accepted 2021-04-12

Note

(C) 2021 by Abhishek Kumar, Nilu Kumari, Ranjeet Kumar Singh, Alok Kumar, V K Singh and Published by Siddharth Health Research and Social Welfare Society. This is an Open Access article licensed under a Creative Commons Attribution 4.0 International License hittps://creativecommons.org/licenses/by/4.0/ unported [CC BY 4.0]. 


\section{Introduction}

Novel coronavirus 2019 (Covid-19) has infected individuals across all age groups. Based on available studies, older age and comorbidities have been found to be associated with higher prevalence and poor clinical outcome $[1,2]$.

Though overall disease appears to be mild in the pediatric age group, the presence of preexisting comorbidities have been found to be associated with severe disease and requirement of ICU care $[3,4]$. The presence of pre-existing illness (comorbidities) appears to alter the natural course of disease across all age groups, making the individual more susceptible to severe disease. It can be presumed that individuals without comorbidities are having different disease characteristics.

We studied the clinical characteristics and outcome of Covid-19 in two age groups without any preexisting illness, children (up to 12 years) and middle-aged adults (40-59 years). We compared the two groups to find whether children are specially protected subgroups as described in previous studies

\section{Materials and methods}

Study design: It was a retrospective observational study

Study setting: The study was conducted at Central Hospital, Ramgarh, a dedicated covid hospital in the Eastern state of Jharkhand.

Study period: The study included patients admitted from May 2020 to October 2020.

Study population: Study included adult patients in the age group 40 to 59 years and pediatric patients up to 12 years of age.

Inclusion criteria: Admitted patients with SARSCov-2 positive result on RT PCR testing of nasopharyngeal swab and falling in two age groups, first age group consisted of middle-aged adults between 40-59 years of age and the second age group consisted of children up to 12 years of age.

Exclusion criteria:All patients in the study age groups suffering from any preexisting medical illness like Diabetes, Hypertension, Cardiovascular disease, Chronic lung disease, chronic liver disease, chronic kidney disease, haematological conditions, malignancies.
Data collection procedure: Details of all enrolled patients were noted in a predesigned proforma which included details like age, sex, history of contact, history of travel to an endemic area, presenting complaints, clinical examination, investigations, treatment received. The total duration of disease was taken as the interval between the first RTPCR Positive report to first RTPCR Negative report.

Statistical analysis- Data was entered into MS Excel and was statistically analysed using PSPP software (available freely at www.gnu.org). Continuous variables of normal distribution were expressed as mean and standard deviation and were compared using unpaired two-tailed t-test. Categorical data were summarized as numbers and percentages and compared using chi-square or Fisher exact test.

\section{Results}

Out of a total of 582 patients admitted during the study period across all age groups, a total of 154 patients in the age group 40- 59 years and 27 patients in the pediatric age group ( up to 12 years ) were enrolled after applying the exclusion criteria. In the middle-aged group sex ratio was 2.9 with 115 males against 39 females. The median age (IQR) of patients was $50(45-53)$ years. 110 (71.4\%) patients had a history of contact with Covid positive individuals. $36(23.4 \%)$ had a history of travel from hotspot areas of the country.34(22.0\%) were completely asymptomatic during the entire stay period. Out of symptomatic patients, cough 66 $(42.8 \%)$ followed by fever $51(33.1 \%)$ were the most common complaints. Sore throat 20 (12.9\%), headache 20(12.9\%), vomiting 14 (99.0\%), diarrhoea $8(5.1 \%)$ were other complaints. Fatigue and myalgia were reported in 19 (12.3\%),6 (3.8\%) patients respectively.11(7.1\%) patients were classified as having severe disease.66 (42.8\%) initially presented with respiratory symptoms. Breathlessness was present in 15 (9.7\%) patients, requiring oxygen therapy. $11(7.1 \%)$ needed ICU admission. IV antibiotics were given to 15 patients. $15(9.7 \%)$ were given steroids and $6(3.8 \%)$ required anticoagulants. Oral Azithromycin and Hydroxychloroquine were given to 120 (77.9\%) as per the existing protocol [5]. One patient expired and the rest 153 were successfully discharged after getting declared negative on RT PCR testing as per prevalent guidelines. 
Table I illustrates the clinical characteristics of patients in both age groups. In the pediatric age group, out of a total of 27 patients enrolled, 17 were males with a skewed sex ratio of 1.7 and median age (IQR) was 6 (4-9) years.25 (92.5\%) children had a history of exposure from infected family members while in rest 2 (7.4\%) children source of infection could not be ascertained.17(62.9\%) children were asymptomatic. Among symptomatic children cough (18.5\%)and fever $(18.5 \%)$ were the most common complaints followed by sore throat $3(11.3 \%)$, diarrhoea $1(3.7 \%)$ and vomiting $1(3.7 \%)$. Although $5(18.5 \%)$ children had respiratory complaints, none of them had breathlessness or desaturation and none required ICU care.
Oral antihistaminics and Azithromycin were given to $5(18.5 \%)$ children each. There was no expiry and all children were discharged successfully. There was no significant difference between the two age groups concerning sex and disease severity. mean duration of disease as decided by RT PCR positivity was also not significantly different in the two age groups. The children group had a significantly higher number of asymptomatic cases whereas the middle-aged group had a significantly higher number of cases with respiratory complaints like cough, while fever was not significantly different in the two groups.

Table I: Clinical characteristics of patients in both age groups

\begin{tabular}{|c|c|c|c|}
\hline Characteristics & 40- 59 years & Up to 12 years & P value* \\
\hline Total No. of patients & 154 & 27 & \\
\hline Age: Median (IQR) & $50(45-53)$ & $6(4-9)$ & \\
\hline Gender: Male/Female & $115 / 39(2.9: 1)$ & $17 / 10(1.7: 1)$ & 0.241 \\
\hline \multicolumn{4}{|l|}{ Mode of exposure } \\
\hline $\mathrm{H} / \mathrm{O}$ contact present & $110(71.4)$ & $25(92.5)$ & \\
\hline $\mathrm{H} / \mathrm{O}$ contact not present & $44(28.6)$ & $2(7.4)$ & \\
\hline $\mathrm{H} / \mathrm{O}$ travel from an endemic region & $36(23.6)$ & & \\
\hline \multicolumn{4}{|l|}{ Disease severity } \\
\hline Severe & $11(7.1)$ & 0 & 0.374 \\
\hline Non-severe & $143(92.9)$ & $27(100)$ & \\
\hline \multicolumn{4}{|l|}{ Clinical features } \\
\hline Asymptomatic* & $34(22.8)$ & $17(62.9)$ & $<0.001$ \\
\hline With respiratory symptoms* & $66(42.8)$ & $5(18.5)$ & 0.018 \\
\hline Fever & $51(33.1)$ & $5(18.5)$ & 0.175 \\
\hline Cough* & $66(42.8)$ & $5(18.5)$ & 0.018 \\
\hline Sore throat & $20(12.9)$ & $3(11.1)$ & \\
\hline Nausea/vomiting & $14(9.0)$ & $1(3.7)$ & \\
\hline Diarrhoea & $8(5.1)$ & $1(3.7)$ & \\
\hline Headache & $20(12.9)$ & 0 & \\
\hline Fatigue & $19(12.3)$ & 0 & \\
\hline Myalgia & $6(3.8)$ & 0 & \\
\hline Breathlessness & $15(9.7)$ & 0 & \\
\hline Desaturation & $11(7.1)$ & 0 & \\
\hline \multicolumn{4}{|l|}{ Treatment } \\
\hline Azithromycin & $120(77.9)$ & $10(77.9)$ & \\
\hline Hydroxychloroquine & $120(77.9)$ & 0 & \\
\hline Antihistaminics & $66(42.8)$ & $5(18.5)$ & \\
\hline ICU admission & $11(7.1)$ & 0 & \\
\hline Oxygen therapy & $15(9.7)$ & 0 & \\
\hline IV Antibiotics & $15(9.7)$ & 0 & \\
\hline Steroids & $15(9.7)$ & 0 & \\
\hline Anticoagulants & $6(3.8)$ & 0 & \\
\hline Infiltrates on Chest $\mathrm{X}$ ray & & & 0.421 \\
\hline
\end{tabular}




\begin{tabular}{|l|l|l|l|}
\hline $\begin{array}{l}\text { Unilateral infiltrates } \\
\text { Bilateral infiltrates }\end{array}$ & $\begin{array}{l}14(9.0) \\
15(9.7)\end{array}$ & $\begin{array}{l}2(7.4) \\
1(3.7)\end{array}$ \\
\hline Outcome & $\begin{array}{l}1(0.6) \\
153(99.4)\end{array}$ & $\begin{array}{l}0 \\
27(100)\end{array}$ & 1.00 \\
\hline $\begin{array}{l}\text { Death } \\
\text { Discharge }\end{array}$ & $12.48( \pm 3.73)$ & $12.28( \pm 5.69)$ & 0.409 \\
\hline Mean duration of disease \# &
\end{tabular}

All values in No. (\%), except median (IQR)

\# Duration in days: Mean (standard deviation)

$* \mathrm{P}$ value $<0.05$ was considered statistically significant

\section{Discussion}

The study investigates the clinical characteristics of covid-19 infection, in healthy individuals in two age groups, middle-aged and children, and tries to decipher the sole impact of age on the natural course of the disease. In the middle-aged group, the sex ratio was more skewed in favour of males than in the children group. This may be because this is the earning age group of society where males are more exposed to the infection. This sex ratio was comparable to previously reported Indian study [6].

In the children group also male preponderance was noticed, similar to previous studies $[3,7]$. The median age group of adults in our study was higher than previous reports $[6,8]$, because we only included middle-aged individuals between 40 to 59 years in our adult study group. Most children acquired the disease from infected family members. Such family clustering of pediatric cases has also been documented previously $[3,7,9]$ But in adults many patients had no traceable contacts $(28.6 \%$ in our study), indicating wider exposure sources for this age group.

$62.9 \%$ of children in our study were asymptomatic, this is higher than the numbers reported in a previous study $[10,11]$, which may be because we excluded children with comorbidities. However the number of asymptomatic patients in the adult group was $22 \%$ which is lower than the number reported previously (44.4\%) in a North Indian study [6].

This may be because our study population was relatively older with a median age of 50 years when compared to the mean age of their study population (40.1 years). These findings do confirm the fact that as age increases chances of symptom manifestation increases.
In our study also, the children group had a significantly higher proportion of asymptomatic cases in comparison to the adult group. These findings reiterate the fact that covid-19 is a mild disease in children as previously observed in several studies.[3,7,9,10,12]. Cough and fever have previously been reported as the most common symptom in both age groups $[6,12,13]$, however we found that an adult with Covid -19 was more likely to have respiratory symptoms in comparison to a child.

In our study, the mean duration of RT PCR positivity in the adult group was 12.4 days. This is comparable to the duration previously reported in a study from Singapore [14]. However this duration was lower than other reports from India [6] and the US [15]. This may be because of no pre-existing illness in our study population, leading to better immunogenic response and quicker viral clearance. However mean duration of disease had no significant difference in the two age groups in our study population reflecting the fact that children may have an advantage over adults when it comes to the severity of disease but they harbour the virus for a similar duration in their body and act as asymptomatic carrier and transmitter of virus.

\section{Conclusion}

Covid 19 is a mild disease in healthy individuals in both children and adults. Although children tend to have more symptom-free infection in comparison to adults, the duration of viral clearance is the same in both age groups. Because of the asymptomatic nature of the infection, children possibly are an important transmitter of Covid-19 infection.

\section{What this study adds to the existing knowledge}

- The duration of Covid-19 infection is similar in children and adults without pre-existing comorbidities.

- Children tend to harbour more asymptomatic infection in comparison to adults 


\section{Contributors Details}

Abhishek Kumar ( $A K$ ), conceptualized the study, collected and analysed the data, wrote the manuscript and will act as the guarantor. Nilu kumari (NK) and Alok Kumar (AK) contributed to collecting data and writing the manuscript, Ranjeet Kumar Singh (RKS), and V K Singh (VKS) contributed by giving critical inputs and writing the manuscript. All authors approved the final manuscript.

\section{Reference}

01. Richardson S, Hirsch JS, Narasimhan M, Crawford JM, McGinn T, Davidson KW, et al. Presenting Characteristics, Comorbidities, and Outcomes Among 5700 Patients Hospitalized With COVID-19 in the New York City Area. JAMA. 2020 May 26;323(20)2052-2059.

doi: $10.1001 /$ jama.2020.6775 [Crossref]

02. Bajgain KT, Badal S, Bajgain BB, Santana MJ. Prevalence of comorbidities among individuals with COVID-19- A rapid review of current literature. Am J Infect Control. 2021 Feb;49(2)238-246.

doi: $10.1016 /$ j.ajic.2020.06.213 [Crossref]

03. Götzinger F, Santiago-García B, Noguera-Julián A, Lanaspa M, Lancella L, Calò Carducci FI, et al. COVID-19 in children and adolescents in Europe- a multinational, multicentre cohort study. Lancet Child Adolesc Health. 2020 Sep;4(9)653-661.

doi: $10.1016 / \mathrm{S} 2352-4642(20) 30177-2$ [Crossref]

04. Rao S, Gavali V, Prabhu SS, Mathur R, Dabre LR, Prabhu SB, Bodhanwala M. Outcome of Children Admitted With SARS-CoV-2 InfectionExperiences From a Pediatric Public Hospital. Indian Pediatr. $2021 \mathrm{Apr} 15 ; 58(4) 358-362$.

doi: $10.1007 / \mathrm{s} 13312-021-2196-4 \quad$ [Crossref]

05. Revised guidelines on clinical management of Covid 19. Govt of India, MoHFW. DGHS(EMR Division). 31st March 2020 p 18.

Available at: [Article] [Crossref]
06. Mohan A, Tiwari P, Bhatnagar S, Patel A, Maurya A, Dar L, et al. Clinico-demographic profile \& hospital outcomes of COVID-19 patients admitted at a tertiary care centre in north India. Indian J Med Res. 2020 Jul \& Aug;152(1 \& 2)6169.

doi: 10.4103/ijmr.IJMR_1788_20 [Crossref]

07. Sarangi B, Reddy VS, Oswal JS, Malshe N, Patil $A$, Chakraborty $M$, et al. Epidemiological and Clinical Characteristics of COVID-19 in Indian Children in the Initial Phase of the Pandemic. Indian Pediatr. 2020 Oct 15;57(10)914-917.

doi: $\quad 10.1007 / \mathrm{s} 13312-020-1994-4 \quad$ [Crossref]

08. Gupta N, Ish P, Kumar R, Dev N, Yadav SR, Malhotra $\mathrm{N}$, et al. Evaluation of the clinical profile, laboratory parameters and outcome of two hundred COVID-19 patients from a tertiary centre in India. Monaldi Arch Chest Dis. 2020 Nov 9;90(4).

doi: $10.4081 /$ monaldi.2020.1507 [Crossref]

09. Guo CX, He L, Yin JY, Meng XG, Tan W, Yang GP, et al. Epidemiological and clinical features of pediatric COVID-19. BMC Med. 2020 Aug $6 ; 18(1) 250$.

doi: 10.1186/s12916-020-01719-2 [Crossref]

10. Meena J, Yadav J, Saini L, Yadav A, Kumar J. Clinical Features and Outcome of SARS-CoV-2 Infection in Children- A Systematic Review and Meta-analysis. Indian Pediatr. 2020 Sep $15 ; 57(9) 820-826$.

doi: 10.1007/s13312-020-1961-0 [Crossref]

11. Banerjee S, Guha A, Das A, Nandi M, Mondal R. A Preliminary Report of COVID-19 in Children in India. Indian Pediatr. 2020 Oct 15;57(10)963964.

doi: $\quad 10.1007 / \mathrm{s} 13312-020-2004-6 \quad$ [Crossref]

12. Ruan PS, Xu HQ, Wu JH, Song QF, Qiu HY. COVID-19 in Children- Clinical Characteristics and Follow-Up Study. SN Compr Clin Med. 2020 Sep 3;1-4.

doi: $10.1007 / s 42399-020-00502-x \quad$ [Crossref] 
13. Wang $P$, Sha J, Meng $M$, Wang $C$, Yao Q, Zhang $Z$, et al. Risk factors for severe COVID-19 in middle-aged patients without comorbidities- a multicentre retrospective study. J Transl Med. 2020 Dec 7;18(1)461.

doi: $10.1186 / s 12967-020-02655-8 \quad$ [Crossref]

14. Young BE, Ong SWX, Kalimuddin S, Low JG, Tan SY, Loh J, et al. Epidemiologic Features and Clinical Course of Patients Infected With SARSCoV-2 in Singapore. JAMA. 2020 Apr $21 ; 323(15) 1488-1494$.

doi: $10.1001 /$ jama.2020.3204 [Crossref]

15. Gombar S, Chang M, Hogan CA, Zehnder J, Boyd S, Pinsky BA, et al. Persistent detection of SARS-CoV-2 RNA in patients and healthcare workers with COVID-19. J Clin Virol. 2020 Aug; $129 ; 104477$.

doi: $10.1016 / j . j c v .2020 .104477$ [Crossref] 